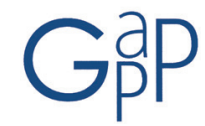

GESTIÓN Y ANÁLISIS DE POLÍTICAS PÚBLICAS, Nueva Época, nº 13 enero-junio 2015 ISSN: 1989-8991

DOI: http://dx.doi.org/10.24965/gapp.voi13.10236

\title{
Modelos educativos y políticas de educación secundaria en Andalucía, Madrid y País Vasco: problemas, agendas y decisiones ${ }^{1}$
}

\author{
Esther del Campo \\ Instituto Complutense de Estudios Internacionales (ICEI-UCM) \\ delcampo@cps.ucm.es \\ Eliseo López Sánchez \\ Universidad Complutense de Madrid \\ eliseorl@cps.ucm.es
}

\begin{abstract}
Resumen
Este artículo pretende explicar y analizar cómo las comunidades autónomas han definido sus diferentes modelos educativos, y políticas de educación secundaria a partir de la ambigüedad del marco jurídico del Estado central, que culmina en la Ley Orgánica de Educación de 2006. Hemos seleccionado tres casos especialmente relevantes y diferentes que nos permiten contrastar como se configuran los modelos educativos autonómicos: El País Vasco, Andalucía y la Comunidad de Madrid. El análisis se centra en los elementos clave de la legislación del Estado para las comunidades autónomas, tales como la autonomía de gestión de los institutos públicos, el papel de la comunidad de actores implicados, los conciertos con los colegios privados y la adaptación de las políticas a las diferencias sociales entre comunidades autónomas. Tomando el enfoque de corrientes múltiples de Zahariadis como herramienta de análisis, el artículo concluye señalando la importancia del medio ambiente social y su impacto en las políticas, la relevancia de la ideología del partido gobernante en cada comunidad autónoma y la participación de los actores en la implementación de políticas de educación secundaria.
\end{abstract}

Palabras clave

Políticas de educación secundaria, comunidades autónomas, enfoque de corrientes múltiples, procesos de decisión, problemas públicos

\section{Educational models and secondary educational policies in Andalusia, Madrid and the Basque Country: problems, agendas and decisions}

Abstract

This article aims at explaining and analyzing how Autonomous Communities have defined their different educational models and policies for secondary education from an ambiguous legal framework in central State, culminating in the Organic Education Law in 2006. We have selected three particularly relevant and different cases, which allow us to contrast as the regional educational models are configured: the Basque Country, Andalusia and Madrid Region. The analysis focuses on key elements of State legislation, such as the management autonomy of high schools, the role of stakeholders involved in this policy, the outsourcing contracts with the private schools and the adaptation of policies to social differences between Autonomous Communities. Based on Zahariadis' multiple streams model, this article concludes by pointing out the importance of the social environment context and its impact on the policies, the relevance of the ruling party's ideology in each Autonomous Community and the involvement of stakeholders in the implementation of secondary education policy.

Key words

Secondary educational policies Autonomous Communities, multiple streams, decision making processes, public problems

$1 \quad$ Este artículo se enmarca en el proyecto de investigación: “Descentralización y (des)igualdad en el Estado Autonómico: ideología y partidos, opinión pública, financiación territorial y políticas públicas", financiado por el Plan Nacional de I+D Ref: CSO2011-27547 entre 2012 y 2015, y dirigido por la Dra. Raquel Gallego de la Universidad Autónoma de Barcelona. 


\section{INTRODUCCIÓN}

En este artículo buscamos analizar las políticas de educación secundaria en tres comunidades autónomas (Andalucía, Madrid y País Vasco) que han desarrollado modelos de políticas definidos y muy diferentes, de cara a responder cuatro preguntas fundamentales: ¿Por qué han desarrollado modelos tan distintos si el marco general estatal es el mismo?; ¿Qué criterios siguen para fijar sus políticas?; ¿Se adaptan a las situaciones diferentes de cada Comunidad?; y, finalmente, ¿Integran en los procesos de definición de problemas y objetivos a los actores sociales?

Partiendo de un mismo marco estatal, cada uno de los tres casos seleccionados han ido desarrollando su propia trayectoria a partir del traspaso de la competencia a las comunidades autónomas (CCAA), que en cada autonomía ha sido en un momento diferente. No obstante, estas trayectorias se ven impactadas por la promulgación en 2006 de la Ley Orgánica de Educación (LOE), que supuso una oportunidad para que las CC.AA. pudieran rediseñar sus trayectorias, ya que el nuevo texto legal permitía un mayor margen para que éstas pudieran establecer nuevas reglas y normas sobre aspectos que hasta entonces eran ambiguos, y confirmaran o cambiaran otros que la nueva Ley estatal pretendía impulsar, como la mayor autonomía de los centros de educación secundaria.

Para analizar estos elementos, utilizaremos como referente teórico las aproximaciones de equilibrio puntuado o interrumpido (punctuated equilibrium theory) de Baumgartner y Jones (1993), True, Jones y Baumgartner (1999, 2007); y, por otro lado, la perspectiva de corrientes múltiples (multiple streams) desarrollada por Kingdon (1995) y luego retomada por Zahariadis $(1999,2007)$. Consideramos que estos enfoques teóricos son una herramienta muy útil para ayudarnos a responder a las preguntas de investigación antes reseñadas.

El enfoque de equilibrio interrumpido otorga un papel importante a las ideas (paradigmas de políticas, sistemas de creencias e imágenes de políticas) y a la exitosa difusión de éstas como medios para entender los cambios en las expectativas de los actores o miembros de una coalición de actores (gubernamentales y no gubernamentales), así como explica los cambios y continuidades de las políticas. Además, asume el subsistema de la política como unidad de análisis predominante (True, Jones y Baumgartner, 1999), lo que es especialmente útil en este caso, en el que se analiza el subsistema de la política de educación secundaria en cada una de las tres comunidades autónomas antes citadas. La importancia del subsistema de políticas y de los cambios que se producen en ésta, definidos como "sistemas de decisión", que se organizan alrededor de una serie de programas o cuestiones (True, Jones y Baumgartner, 1999:99).

En estos subsistemas, se presume una cierta racionalidad de los actores, que unido a la complejidad y ambigüedad del entorno, dificultan las decisiones racionales de éstos, que pasan a depender de criterios de oportunidad, de los mismos sesgos cognitivos incorporados por los individuos u organizaciones o por el número de cuestiones que compiten por captar la atención de los actores (Zahariadis, 1999: 75-76).

El modelo explica los cambios en las trayectorias de las políticas públicas a partir de la inferencia de actores o acontecimientos externos al ámbito de decisión del subsistema, originando un cambio en la formación de la agenda de la política. Este cambio se produciría en tres niveles: en la imagen y definición que se tiene del problema; en las áreas o sectores de políticas; y en el cuestionamiento de las estructuras de toma de decisión del subsistema.

Por su parte, el enfoque de corrientes múltiples identifica tres corrientes (la corriente de problemas, la corriente de políticas públicas y la corriente de política), cuyo acoplamiento en un tiempo concreto genera ventanas de oportunidad para que los promotores de políticas puedan incluir un tema en la agenda de gobierno. La ventana de la corriente de las políticas públicas se abre cuando el intercambio de ideas entre los actores especializados en una materia produce un nuevo consenso sobre los valores aceptables. La ventana de la corriente de problemas se abre cuando los sucesos o las circunstancias de la sociedad se convierten en problemas públicos. Y, por último, la ventana de la corriente de la política se abre cuando un tema entra en el campo de la ideología de los partidos de gobierno (Zahariadis, 1999).

En este modelo, la decisión depende de un tira y afloja de numerosos factores y actores que influyen en un sistema político y que se producen en un entorno de ambigüedad, en el que existe más de una definición de problema público sobre un tema o conflicto social y las preferencias de los actores son difusas (Zahariadis, 1999).

Ambos modelos buscan explicar cómo y por qué se producen los cambios en las políticas públicas, partiendo de que éstas tienden a buscar un equilibrio en el que mantenerse, con cambios incrementales. Este mantenimiento incremental de un cierto equilibrio marca una trayectoria de la política, una trayectoria en cada subsistema de política, del que tenemos que partir, y al que impacta un evento externo que puede producir el cambio en la política (Barzelay y Gallego, 2006 y 2010). 
En nuestro caso son tres subsistemas de política de educación secundaria en tres comunidades autónomas a las que la LOE supone un impacto que puede producir un cambio en la política. Así, el texto parte de la descripción de la situación de partida de esta política desde el ámbito del Estado central, que se caracteriza por el conflicto, y que ha traspasado la competencia sobre educación secundaria en diferentes momentos a las comunidades autónomas. Los sucesivos marcos legales estatales han ido impactando sobre la definición y trayectoria de las políticas de las comunidades autónomas, culminando en 2006 con la aprobación de la Ley Orgánica de Educación, que ha supuesto una oportunidad igual para todas ellas de redefinir, o no, sus políticas educativas. A continuación el texto describe y analiza los casos particulares de País Vasco, Andalucía y Comunidad de Madrid y, por último, concluye con una breve reflexión comparada en torno a los tres casos estudiados.

La investigación se ha basado en dieciocho entrevistas personales a responsables políticos y actores sociales de las tres comunidades autónomas y del Estado central, así como en la documentación técnica existente y la aportada por los mismos actores gubernamentales y sociales. Se trata, por tanto, de una aproximación cualitativa, descriptiva-explicativa, que parte de la inferencia de la información y opiniones expresadas por los mismos actores, y que a través de tres estudios de caso persigue hacer un análisis comparado de la identificación de los problemas principales así como de los procesos de toma de decisión.

\section{LA TRAYECTORIA DE LA POLÍTICA PÚBLICA EN EL ESTADO CENTRAL}

De manera sintética, podemos establecer que, actualmente, las políticas de educación secundaria en España son una competencia autonómica a nivel de ejecución y desarrollo normativo, mientras que el marco legal general es competencia del Estado central. No obstante, este resultado final se ha ido implantando en diferentes momentos en cada territorio, ya que la competencia ha sido traspasada también en distintas etapas a las comunidades autónomas.

El rasgo más destacado de la política educativa a nivel estatal es la ambigüedad (no la incertidumbre), ya que cada cambio de mayoría parlamentaria conducía a introducir de nuevo en la agenda gubernamental esta política, reformulada aunque no se hubiera implementado. No obstante, se ha ido definiendo una trayectoria en la política educativa del Estado central, que desde los años 80 ha ido estableciendo varios elementos en el ámbito de decisión estatal, dejando otros a la autonomía de decisión de los órganos políticos autonómicos.

Entre los temas que deciden los órganos del Estado central más importantes están:

- Un porcentaje del contenido curricular, esto es, de las asignaturas y contenidos de las mismas.

- Los procedimientos de promoción del alumnado.

- Los tipos de centros según su gestión: gestión directa, externalización (gestión privada con concierto) y privados.

- Los criterios de selección de los profesores.

Sobre este modelo general, las sucesivas leyes orgánicas han ido dejando un espacio de decisión a las comunidades, que les ha permitido perfilar modelos educativos diferentes. Así, las comunidades autónomas han ido definiendo sus propias trayectorias de políticas educativas, y particularmente de educación secundaria. En este sentido, podemos identificar también varios temas clave que los políticos autonómicos han tenido que definir:

- Un porcentaje del contenido curricular, fundamentalmente deciden las asignaturas optativas y sus contenidos.

- La gestión de los centros educativos en su territorio, incluyendo los de gestión directa y los concertados, ya que son las administraciones autonómicas las que firman los conciertos o convenios de externalización y las condiciones de los mismos.

- La selección de los profesores, en todos los tipos de contratación. También seleccionan todo el personal de la administración pública de educación.

- $\quad$ Los criterios de selección de los alumnos en los centros.

Con estas capacidades, cada comunidad autónoma ha ido configurando su propio modelo educativo, teniendo en cuenta dos aspectos fundamentales, cuándo fue traspasada la competencia de educación y el color político de la mayoría parlamentaria del Estado central. 
Respecto a este color político del Estado central, hemos de señalar que en España no existe un acuerdo entre los dos principales partidos políticos de ámbito nacional, Partido Popular (PP) y Partido Socialista Obrero Español (PSOE), respecto al conjunto del modelo educativo, incluida la educación secundaria. Así, se han venido produciendo cambios en la trayectoria en los aspectos polémicos cada vez que se ha producido un cambio de mayoría de gobierno. Estos aspectos polémicos de la política educativa del ámbito de decisión del Estado central han afectado a los porcentajes de los contenidos curriculares que pueden establecer las comunidades autónomas y el idioma en el que se imparten, a determinadas asignaturas obligatorias ${ }^{2}$, a los procedimientos de selección del alumnado y a los tipos de centros educativos en los que se presta este servicio público.

Hay que señalar además que el punto de partida previo era una Ley General de Educación (14/1970, LGE) de 1970 que supuso el intento de los últimos gobiernos franquistas para adecuar el sistema de enseñanza a los principios meritocráticos y a construir una educación funcional para el desarrollo y el crecimiento económico (Bonal, 2002:14). La extensión de la educación obligatoria y gratuita hasta los 14 años y, sobre todo, la universalización del servicio constituían las medidas más significativas³ de una ley calificada de "ambiciosa y utópica" (Subirats, 1975: 2) y que jamás se implementó en su totalidad, tanto por falta de financiación como por falta de voluntad política (Bozal y Paramio, 1975), a pesar de que la universalización del servicio incluía la prestación por centros privados.

Respecto a los centros públicos de educación secundaria, éstos se gestionaban de manera jerárquica, burocrática y centralizada, dependiendo de una estructura ministerial que se repartía en direcciones provinciales, con una autonomía de decisión escasa. Junto a estos centros públicos existían multitud de centros privados, mayoritariamente de propiedad y gestión de órdenes religiosas católicas, aunque también existían centros privados de educación secundaria de carácter laico, propiedad de particulares o de cooperativas, de profesores o de padres. El reparto en el territorio de este conjunto de centros era muy desigual, existiendo desigualdades importantes entre unas y otras provincias. En términos generales y como manifiestan los actores entrevistados, se podía afirmar que los centros privados se concentraban en las zonas urbanas, y más en el norte de España que en el sur, por lo que los centros privados estaban establecidos en las zonas de mayor renta, mientras que las zonas de España de menor renta debían ser cubiertas por las administraciones públicas, lo que se hacía de forma incompleta.

La implementación de la LEG acabó siendo instrumentalizada por el sector privado religioso (Gómez Llorente, 1983; Boix y García, 1985) y a partir de 1971 se tradujo en el establecimiento de medidas contrarias al espíritu de la propia Ley ${ }^{4}$, facilitando la hegemonía del sector privado religioso en el sistema español de enseñanza (Bonal, 2002: 14).

Una vez que entró en vigor la actual Constitución Española de 1978 (CE)5 , el Gobierno de Adolfo Suárez se planteó adaptar el sistema educativo español al nuevo régimen político. Se elaboró un nuevo texto legal, la Ley Orgánica que regulaba el Estatuto de Centros Escolares (LOECE, de 19 de junio de 1980). Esta Ley originó un fuerte enfrentamiento con el PSOE, principal partido de la oposición en ese momento, y puso en evidencia los principales temas de debate en la política educativa española: el grado de autonomía de los centros de enseñanza, la regulación de la participación de la comunidad educativa en el control y gestión de la escuela y, sobre todo, el paso de un sistema de subvenciones a uno de conciertos en el sector de la enseñanza privada. La falta de acuerdo hizo que el PSOE llevara la Ley al Tribunal Constitucional, que invalidó en 1981 gran parte de sus postulados. Debido a la inestabilidad política del momento, con un intento de Golpe de Estado, el asunto perdió prioridad en la agenda gubernamental y la Ley nunca entró en vigor.

El siguiente hito se produjo en 1985, con el Gobierno que presidía el socialista Felipe González. La Ley Orgánica del Derecho a la Educación (LODE, 8/1985, de 3 de julio) supuso una reestructuración del sistema de conciertos

2 Particularmente polémico sigue siendo el caso de la asignatura de religión aunque en realidad los cambios afectan a más asignaturas y a las horas de diferentes asignaturas, como lengua y matemáticas.

3 La Ley también contemplaba la creación de la Enseñanza General Básica (EGB), la unificación del Bachillerato (BUP), la creación de la Formación Profesional y la universalización del acceso a la universidad.

4 Por ejemplo, política de numerus clausus, paralización de las inversiones públicas en equipamientos, subvenciones indiscriminadas a los centros privados, etc.

5 El artículo 27 de la CE recogía los aspectos básicos del denominado "pacto escolar" que tenía como aspectos fundamentales: el derecho a la educación, la gratuidad y obligatoriedad de la educación básica, la responsabilidad por parte de los poderes públicos de la inspección y la homologación del sistema educativo a otros Estados europeos. En el pacto, el derecho de las familias a que sus hijos pudieran recibir formación religiosa y moral, la libertad de creación de centros docentes o la consolidación de un sistema educativo dual, público y privado, garantizado por los poderes públicos, fueron aceptados por la izquierda política. Por su parte, la derecha aceptó la posibilidad de introducir otras lenguas del Estado en la enseñanza, la participación de la comunidad educativa en el control y gestión de todos los centros sostenidos por la Administración pública, la no obligatoriedad de la formación religiosa y la libertad de conciencia y de cátedra del profesorado (Bonal, 2002:15). 
entre la Administración pública y los centros privados que deseasen optar a financiación pública. Se pasó de un sistema de subvenciones indiscriminadas a un sistema de transferencias sujetas a los criterios establecidos por la Administración pública, a cambio de integrarse en el sistema público y ofrecer la educación obligatoria en condiciones de gratuidad. Respecto a la gestión de los centros, pasaron a tener un Consejo Escolar, compuesto por asociaciones de padres y madres de alumnos (AMPAS), representantes de los propios estudiantes de los centros y los profesores de los mismos. En los centros públicos, el claustro de profesores era el que elegía a los directores, entre uno de ellos.

Aunque aparentemente los centros públicos de educación secundaria adoptaban una gestión más autónoma, en la práctica la aplicación de las normas establecidas por los órganos centrales de la administración y la asignación y control presupuestario hacía que la gestión de los centros fuera poco autónoma. De hecho, con la LODE los consejos escolares no podían elegir un proyecto educativo propio para su centro, decidiendo las formas de docencia de las diferentes asignaturas, o la especialización en ciertos contenidos mediante asignaturas optativas.

Los centros privados que firmaron los conciertos con el Ministerio de Educación, o con las consejerías autonómicas en el caso de que ya se hubiera producido el traspaso de competencias en educación asumían los contenidos curriculares de asignaturas y, en teoría, deberían ocuparse de los alumnos que residieran en la zona asignada por la administración pública correspondiente y que solicitaran matricularse en su centro. Sin embargo estos centros tenían mayor autonomía de gestión, aunque para desarrollar sus orientaciones lo tuvieran que hacer mediante contenidos extracurriculares o actividades extra-escolares.Además, sus consejos escolares y sus claustros de profesores tenían un papel de control menor que en los centros públicos.

Hay que señalar que un problema que buscaba solucionar el Gobierno de Felipe González en 1985 era la saturación de la red de centros públicos, debido a que llegaban a edad escolar los niños nacidos desde mediados de los años 60 a mediados de los 70. Ya que la natalidad había bajado posteriormente, la alternativa de construir nuevos centros educativos de gestión directa se desechó, puesto que se hubieran quedado sin alumnos para finales del siglo.

Este modelo de la LODE es el que comenzaron a implementar las CC.AA de vía rápida ${ }^{6}$ que recibieron la competencia antes de 1985, en un contexto en el que hay que tener en cuenta que la Constitución no profundizó en el reparto competencial, dejando la puerta abierta a procesos de negociación y posible conflicto entre el Estado y las comunidades autónomas.

Durante la Presidencia de Felipe González se publicó otra polémica ley que complementaba la anterior, la Ley Orgánica de Ordenación General del Sistema Educativo, (LOGSE, 1/1990, de 3 de octubre). Esta Ley afectó fundamentalmente a los procedimientos de promoción del alumnado, al cambio de asignaturas y al contenido de las mismas, dejando la doble red de centros intacta. En cuanto a la gestión de los centros públicos, la LOGSE estableció que los directores serían elegidos por los consejos escolares, en vez de por el claustro de profesores.

De forma significativa, la LOGSE estableció que la educación secundaria, que en la Ley de 1970 era no obligatoria y para alumnos desde los 14 a los 18 años, pasaba a tener dos partes, una obligatoria para alumnos desde los 12 a los 16 años, la Educación Secundaria Obligatoria (ESO), y una segunda etapa no obligatoria, el Bachillerato, para alumnos desde los 16 a los 18 años y orientada a la entrada directa en la Universidad, que era alternativa a la Formación Profesional Específica de Grado Medio, más orientada al mercado laboral.

Además, la LOGSE también introdujo en cada centro de gestión directa mejoras como el ratio de un máximo de 30 alumnos por aula, orientadores, profesores de apoyo para alumnos con dificultades, programa de formación permanente del profesorado y un papel más relevante de la inspección educativa. Al tiempo, se consolidaron los conciertos con los colegios privados, al pasar a entenderlos como un derecho de los padres a elegir la educación de sus hijos, y no como una solución coyuntural a un problema de exceso temporal de demanda.

En 1995, poco antes de finalizar el periodo de mayorías parlamentarias socialistas, se publicó la Ley Orgánica de Participación, Evaluación y Gobierno de los Centros Educativos (LOPEG, 9/1995 de 20 de noviembre), que fundamentalmente modernizaba la LODE, y destacaba el papel de los Consejos escolares en los centros públicos. Esta ley supuso la confirmación de la trayectoria de la política educativa de los gobiernos del PSOE entre 1983 y 1996 , que se definía por sus contenidos curriculares, los procedimientos de promoción del alumnado, los elementos de

6 Se entiende por comunidades de vía rápida las que accedieron a la autonomía por la vía del artículo 151 de la CE (País Vasco, Cataluña, Galicia y Andalucía) junto con Canarias y la Comunidad Valenciana, que accedieron por la vía del artículo 143, pero que consiguieron un nivel competencial semejante a las anteriores mediante dos leyes orgánicas de transferencias. 
apoyo a los alumnos, y la gestión de los centros, con los consejos escolares como controladores y electores de los directores en los centros públicos.

Con la llegada al Gobierno de José María Aznar en 1996, se cuestionó el modelo educativo previo. Sin embargo, el PP no tenía mayoría absoluta en las Cortes Generales y no consiguió apoyo para modificar el marco jurídico estatal hasta el año 2000, que pudo impulsar la Ley Orgánica de Calidad de la Educación (LOCE, 10/2002, de 23 de diciembre), una vez finalizado el traspaso de las competencias a todas las comunidades autónomas en 2001. Esta Ley originó una importante polémica sobre el papel de la asignatura de religión católica y su contenido, así como por cambiar el procedimiento de promoción de los alumnos, considerado por el PP y varios actores sociales implicados en las políticas públicas educativas demasiado flexible y tolerante para los alumnos, produciendo en estos indisciplina, falta de respeto a los profesores y poca valoración del esfuerzo.

La LOCE no llegó a entrar en vigor, ya que su aplicación en el curso 2004-05, coincidió con la llegada al Gobierno de José Luis Rodríguez Zapatero, que la suspendió. Al tiempo, el Gobierno de Rodríguez Zapatero promovió la Ley Orgánica deEducación (LOE, 2/2006, de 3 de mayo) que ha estado en vigor hasta 2014. Dado que el PSOE no tenía mayoría absoluta en las Cortes, la Ley necesitó el apoyo de los partidos de izquierda y partidos nacionalistas catalanes, vascos, canarios y gallegos.

La LOE no modificó los tipos de gestión de los centros públicos, y dejó la firma o no de los conciertos a las comunidades autónomas, incluyendo el pago de las nóminas de los profesores de la educación concertada a cargo del Estado central, aunque ejecutado por las comunidades autónomas. Además, el Gobierno de Rodríguez Zapatero se caracterizó por no entrar en el ámbito de decisión autonómico en la implementación de la LOE.

Podemos entender que la promulgación de la LOE supuso la apertura de una ventana en la corriente de los problemas a nivel autonómico, ya que fue un suceso externo que hizo que los decisores autonómicos debieran prestar atención de nuevo a su modelo educativo, obligándoles a confirmar, o no, sus definiciones de problemas y objetivos, volver a tratar con los actores implicados en la política a nivel autonómico, definir la prioridad de este problema en la agenda gubernamental y con qué tipos de gestión llevar a cabo los objetivos formulados. En definitiva, supuso un impacto o suceso externo en la trayectoria de las políticas educativas autonómicas con el potencial de interrumpir el equilibrio existente en cada subsistema.

Vamos a mostrar este impacto en tres casos especialmente relevantes por cómo han definido sus problemas públicos y han formulado su política. Cada uno de ellos responde a circunstancias diferentes en cuanto a partidos gobernantes y tipos de mayorías a nivel autonómico, redes de actores sociales, momento del traspaso, tipo de financiación.

En resumen, podría decirse que la trayectoria de la política educativa en España ha sufrido de tres errores principales (Bolívar, 2004a). En primer lugar, el diseño de leyes educativas por el partido gobernante y no por el Estado. En segundo lugar son leyes "escolares", ya que se limitan a medidas en el sistema escolar, y no son "educativas", dirigidas a intervenir activa y socialmente en la comunidad. En tercer lugar, tienen una confianza excesiva en las regulaciones administrativas por medio de reformas diseñadas técnicamente, cuando la investigación educativa lleva décadas poniendo de manifiesto (Fullan, 2002; Tyack y Cuban, 2000) que los cambios legislativos no provocan por sí mismos una transformación de las culturas escolares y profesionales, y menos aún de las condiciones sociales para llevarlas a cabo (Beltrán, Hernández i Dobon y Montané, 2008:59).

\section{EL PAÍS VASCO, UN MODELO CENTRADO EN LAS LENGUAS}

El País Vasco recibió las competencias en materia de educación no universitaria básicamente en 1980. Durante los primeros años de ejercicio de la competencia la principal preocupación del Gobierno Vasco se centró en la gestión de los medios materiales del personal transferido. Ambos asuntos fueron tratados en un contexto de creación de estructuras y reglas de funcionamiento del conjunto del Gobierno y Administración de la Comunidad Autónoma Vasca.

La situación inicial heredada del Estado central en el País Vasco en la educación secundaria tenía ciertas peculiaridades respecto al conjunto de España. La prestación del servicio se venía haciendo mediante dos modelos, uno público y otro privado, repartiéndose el conjunto del alumnado prácticamente al $50 \%$.

- El modelo público, cuya prestación del servicio se basaba en una red de institutos públicos de enseñanza gestionados de manera directa por la administración, en un esquema bastante centralizado, jerarquizado y burocrático.

- $\quad$ El modelo privado, que se componía de un conjunto de colegios de propiedad y gestión privada, pero con dos tipos diferentes. Un tipo eran los colegios privados de órdenes religiosas católicas; el otro tipo

GESTIÓN Y ANÁLISIS DE POLÍTICAS PÚBLICAS, Nueva Época, nº 13 enero-junio 2015 - ISSN: 1989-8991 - DOI: 10.24965/gapp.v0i13.10236 
eran colegios formados por cooperativas de padres de alumnos, denominados "Ikastolas". Estas cooperativas de padres se habían formado para dar una educación diferente, con contenidos distintos a los de la educación pública del régimen de Franco y la Ley de 1970, y vinculados en muchos casos a la ideología nacionalista vasca. Estas Ikastolas, extendidas también a Navarra y el País Vasco francés, pretendían desarrollar en cada caso su propio proyecto educativo.

A partir de 1985 la aplicación de la LODE supuso la oportunidad para los actores de la Comunidad Autónoma del País Vasco de desarrollar su propio modelo, y la LOGSE en 1990 consolidó esta oportunidad. Se abría con ello "la ventana de la corriente de problemas", en la que el tema se colocaba como potencial problema público en el ámbito autonómico, aunque para situarlo en la agenda se requería introducirlo en "la corriente de la política”, esto es, encajarlo en los postulados ideológicos de los partidos.

Para contextualizar este análisis, hemos de tener en cuenta que 1985 se produjo un importante conflicto interno en el Partido Nacionalista Vasco, que gobernaba con mayoría absoluta la Comunidad Autónoma desde su creación en 1980. El conflicto supuso unas elecciones autonómicas en 1987, en las que el tema del modelo educativo vasco no se trató en profundidad. Tras esas elecciones se formó un gobierno de coalición entre el PNV y el PSE, sección vasca del PSOE. Esta coalición dejó al PSE la Consejería de Educación, y en este momento se definieron las características del modelo educativo vasco actual, basado en acuerdos entre los nacionalistas del PNV y los socialistas del PSE.

Las bases de este modelo se consolidaron tras las elecciones autonómicas vascas de 1991 y posteriores, con distintas composiciones de gobierno. El PSE permaneció como socio minoritario del gobierno hasta 1998, ocupando la Consejería de Educación. Posteriormente, esta Consejería fue asumida por EuskoAlkartasuna, EA, la formación escindida del PNV en 1985 y que se podría considerar más progresista y laica que el propio PNV. En 2006, al publicarse la LOE, era EA el partido que ocupaba la Consejería de Educación del Gobierno Vasco. No obstante, el momento clave para redefinir los elementos del modelo educativo vasco es el periodo de 2009 a 2012, en el que el PNV ha permanecido fuera del Gobierno Vasco, que estuvo compuesto solo por el PSE, apoyado en el Parlamento Vasco por el PP. Aunque el PNV no ha ocupado la Consejería de Educación entre 1987 y 2012, su presencia como fuerza mayoritaria en las coaliciones de gobierno ha supuesto un elemento muy relevante.

En definitiva, entre 1987 y 1991 se configuraron las características principales del caso vasco, que aunque hayan sido cuestionadas, permanecen:

- Prácticamente todos los centros privados, sean Ikastolas u otro tipo de centros se concertaron como prestadores externos del sistema público, y hoy continúan así. Casi no existe educación privada sin concierto, y los centros concertados mantienen una proporción estable en torno al 50\% respecto a los de gestión pública directa.

- La red pública se centra en las grandes aglomeraciones urbanas, particularmente en las zonas más industriales, aunque está presente también en el resto. No obstante, la zonificación y adscripción del alumnado por su residencia es mayor entre los centros públicos, ya que los padres tienen mucha más libertad para elegir entre las escuelas de secundaria concertadas, a pesar de que esta elección la tienen que sancionar los delegados territoriales de la Consejería de Educación.

- Los centros de enseñanza, ya sean de gestión directa o concertados, tiene que ofrecer tres modelos de enseñanza según la lengua en la que se impartan las asignaturas, a partir de la demanda que tengan por parte de los padres. Estos tres modelos se denominan A, B y D:

A. En castellano, salvo la asignatura de euskera.

B. Mixto, pero con predominio del euskera.

D. En euskera, salvo la asignatura de castellano.

Hay que destacar que los centros de enseñanza secundaria vascos, tanto públicos como concertados, tienen autonomía para elegir que modelos ofertan, y se encargan de formar en lengua vasca a sus profesores de cara a que puedan impartir las asignaturas en una u otra lengua, teniendo en cuenta que la situación de partida era que los profesores que no hablaban castellano era excepcional. Esta autonomía de los centros educativos vascos para ajustarse a la demanda ha sido aprovechada por las direcciones de los mismos para impulsar, en algunos casos, procesos de gestión de calidad, implantando modelos o normalizando procesos bajo su propia iniciativa. 
El principal problema público definido en el sistema educativo vasco ha sido, y es, el lingüístico: el uso del euskera o el castellano en la docencia. La inclusión de este problema en la agenda autonómica fue madurando en el primer periodo de ejercicio de la competencia en educación, coincidiendo con la apertura de las ventanas de las tres corrientes a finales de los años 80, con el gobierno de coalición PNV-PSE. El modelo educativo vasco permitía una solución al problema lingüístico que encajaba dentro de los postulados nacionalistas y socialistas, por lo que abrió la ventana en la corriente de la política, al tiempo que la corriente de los problemas había alcanzado madurez, en el sentido de que la demanda de potenciar el euskera estaba ya definida como problema público, y existía un consenso en los centros universitarios e intelectuales sobre que el sistema educativo era el área en el que había que concentrar los esfuerzos para conseguir que el uso del euskera se expandiera, sin imponerlo de forma obligatoria, simplemente como una opción. Con el tiempo, la evolución de la demanda de los padres y madres ha llevado a que la oferta del modelo A se reduzca en favor del modelo D, aunque menos en las áreas urbanas de las capitales, y también menos en Álava y más en Guipúzcoa. No obstante, esta tendencia al predominio del modelo D es menor si nos circunscribimos a la educación secundaria?.

En cualquier caso, el modelo de triple oferta ha buscado el acomodo entre opciones opuestas, consolidando un subsistema educativo vasco a partir de 1987, iniciando su propia trayectoria. En realidad la construcción del problema público se había realizado en el área de cultura, un área de más interés para el PNV, en el periodo anterior al gobierno de coalición. Desde los sectores nacionalistas se consideraba que el problema principal era el uso de la lengua vasca en la sociedad, y el sistema educativo se consideró el medio para conseguir la extensión de su uso. Por tanto, para el PNV la educación no era un área prioritaria de política. No obstante, si lo era para EA, que también tenía una ideología nacionalista.

En 2006, al publicarse la LOE, el Gobierno vasco se componía de una coalición entre PNV, EA y EB (EzkerBatua), y la Consejería de Educación estaba en manos de EA. Con la nueva Ley se aprovechó para plantear la continuidad, o no, del modelo. El motivo fue que, a pesar de que predominaban los modelos $\mathrm{B}$ y $\mathrm{D}$, el nivel de uso de la lengua vasca en la sociedad se consideraba insuficiente por los nacionalistas, particularmente en las tres capitales provinciales y determinadas zonas, como la zona industrial de Bilbao o el sur de la provincia de Álava. Los responsables políticos nacionalistas constataron que el haber estudiado en euskera no implicaba necesariamente su uso como lengua principal en el resto de los ámbitos de la vida. No obstante, también constataron que la mayor parte de los ciudadanos que habían estudiado desde que se transfirió la competencia eran bilingües y conocían las lenguas castellana y la vasca.

Como alternativa de elección, los responsables de la Consejería se plantearon el modelo catalán, conocido como "inmersión lingüística", aunque finalmente esta opción fue desechada y se continuó con el modelo triple existente.

Tras las elecciones de 2009 se produjo un cambio de Gobierno en el País Vasco, y el PSE formó un Gobierno con un apoyo parlamentario del PP. Para el PSE la educación, tanto primaria como secundaria, constituía un asunto prioritario en su programa. En consecuencia, la educación en todos sus niveles se convirtió en uno de los preferentes temas de la agenda del gobierno del PSE. La existencia de la LOE y el resultado electoral suponían dos impactos sobre la trayectoria de la política educativa vasca que podían interrumpir el equilibrio existente.

Teniendo en cuenta que el PSE había sido un protagonista del diseño e implementación del modelo educativo vigente, podríamos entender que sería reacio a modificarlo y romper el equilibrio en el subsistema de la política. Sin embargo, el Gobierno socialista vasco introdujo modificaciones en el modelo, aunque no lo planteó como una reformulación de la política, sino como un mero añadido al modelo triple tradicional, aunque en la práctica suponía abrir de nuevo las ventanas en las corrientes de la política, de los problemas y de las políticas públicas.

La ventana en la corriente de los problemas se abrió al plantearse que el modelo debía actualizarse porque tenía debilidades, producidas por el tiempo, en el uso de nuevas tecnologías en la educación y en la formación en idiomas extranjeros, particularmente inglés, coincidiendo con la apertura en la ventana en la corriente de la política pública, ya que los diferentes actores coincidían en modernizar el sistema educativo. Frente a esta últi-

7 El modelo A ha pasado de ser elegido por el 64\% de los padres de alumnos de educación secundaria en el curso $1983-84$ (entonces no era obligatoria) al 11,4\% en el curso 2011-12 en la secundaria obligatoria, aunque en bachillerato, la secundaria no obligatoria actual, el porcentaje del modelo A en ese curso era del 38,7\%. Por su parte, el modelo B fue seguido en el curso $2011-12$ por el 26,7\% de los alumnos en la educación secundaria obligatoria y por sólo el 1,6\% en bachillerato, mientras que el modelo D en ese curso fue seguido por el $61,2 \%$ de los alumnos en la obligatoria y por el 59\% en el bachillerato. Fuente: http://www.eustat.es/elementos/ele0002400/ti_Alumnado_de_ense\%C3\%B1anzas_de_regimen_general_no_universitario_de la_CA_de_Euskadi_por_Territorio_Historico_nivel_modelo_de_ense\%C $3 \%$ B B1anza_bilingue_y_titularidad_ Avance_de_datos_20112012/tblo002427_c.html\#axzz3YLZSfSod 
ma debilidad, el Gobierno del PSE planteó un programa de trilingüismo, de manera que en vez de repartir cada modelo en dos lenguas, propuso repartirlo en tres: castellano, vasco e inglés. Aunque inicialmente se debatieron diferentes opciones de porcentajes de tiempo de docencia fijos, al final el programa planteó que los centros públicos y concertados podían introducir el inglés en cada uno de los modelos que ya estuvieran ofertando, dejando al menos el $20 \%$ a cada una de las tres lenguas. En suma, la decisión de introducir o no el programa, quedó en manos de los centros, al igual que los programas de uso de nuevas tecnologías. Al final, los centros que se han acogido al programa ${ }^{8}$, reciben incentivos económicos, mediante formación de profesores en inglés, medios materiales y subvenciones para actividades en inglés.

El impacto del programa de trilingüismo sobre el subsistema educativo vasco es mayor de lo que parece, ya que si se introduce un $20 \%$ de castellano y otro de inglés en un modelo $D$, éste pasaría a ser un modelo $B$ de hecho. A nivel oficial no sucede esto, sino que existe el $D$ tradicional y un modelo $D$ trilingüe, aunque no queda claro cuál sería la diferencia con un modelo B trilingüe que haya introducido el inglés a costa de las horas lectivas en castellano. En realidad esta distinción sería una formalidad, lo que parece que no les importaría tanto a los dirigentes educativos socialistas en el País Vasco. Incluso, el ideal no declarado, hubiera podido ser un modelo trilingüe único, a partir de unos valores de sociedad más integrada e igualitaria, y orientada a un mercado laboral europeo, lo que entraría en el espacio común de las ideologías del PSE y del PP, que le apoyaba en el Parlamento vasco. No obstante, el conflicto con los actores educativos nacionalistas, como sindicatos, asociaciones de padres y de estudiantes, que promovieron movilizaciones y protestas, así como la falta de fuerza parlamentaria del PSE, hicieron que no se expresara el problema público y su solución en estos términos, sino en términos de mejora incremental, de no ruptura del subsistema de la política, por eso el alcance final del programa ha sido limitado.

Al final del periodo de mandato del PSE en 2012, la implementación del programa de trilingüismo era limitada, aunque el equilibrio en el subsistema de la política se había restablecido, pues sigue vigente con el Gobierno del PNV posterior a 2012, manteniéndose como una mejora incremental al modelo triple "de toda la vida". Hay que tener en cuenta que el PNV tampoco obtuvo mayoría absoluta en 2012 y que gobierna con un apoyo parlamentario del PSE.

Hay que destacar que el consenso originado sobre el modelo educativo desde mediados de los años 80 formó una red estable con actores especializados en esta política. Entre estos actores podemos destacar a los sindicatos, CC.OO. y UGT, sindicatos de izquierdas de ámbito del conjunto del Estado; y los sindicatos nacionalistas LAB, ELA y STE-EILAS; ; las asociaciones de madres y padres de estudiantes, como EHIGE y UFEPA, ambas en la esfera del nacionalismo vasco moderado, o patronales como KristauEskola y EHIK, también tendentes al nacionalismo. En conjunto forman una red más bien favorable al nacionalismo y a priorizar a la lengua vasca como el principal problema de la educación secundaria en el País Vasco, manteniendo estable como solución el modelo A-B-D, aunque su opción principal sería un modelo de inmersión lingüística. Por este motivo el equilibrio incrementalista actual es inestable.

No obstante, todavía no se ha abierto una ventana de oportunidades para romper el equilibrio. No parece que la actual LOMCE, impulsada por el Gobierno central del PP en 2014, llegue a ser un suceso de impacto que impulse la corriente de los problemas en el caso vasco y cuestione el actual modelo educativo.

\section{ANDALUCÍA, LA LUCHA CONTRA EL FRACASO Y EL ABANDONO ESCOLAR}

La Comunidad andaluza recibió las competencias básicas en educación no universitaria en 1982 y 1984 , poco antes de que el Estado central publicara la LODE en 1985. A partir de ese momento, el principal objetivo de los sucesivos responsables de la Consejería de Educación en Andalucía fue la adaptación de los recursos materiales y personales traspasados a los requisitos que fijaba dicha Ley, pero teniendo en cuenta que la mayor parte de estos recursos estaban en manos públicas, esto es, que las posibilidades para que Andalucía pudiera establecer conciertos educativos con colegios privados estaba limitada por la escasa cantidad de estos en comparación con otras comunidades autónomas.

La corriente de problemas en materia de educación secundaria en Andalucía en los 80 parecía clara: faltaban servicios, particularmente en las zonas de menos renta. Existía un consenso general sobre este tema y era una prioridad programática para la sección andaluza del PSOE (PSOE-A), partido gobernante con mayoría absoluta en

8110 institutos públicos de secundaria en el curso 2013-14.

9 Existen más sindicatos en la educación secundaria en el País Vasco, pero estos son los más representativos. A nivel histórico STEEILAS ha sido un sindicato minoritario, y actualmente es minoritario en el sistema educativo vasco UGT. 
la década de los $80^{10}$, dominando la corriente de la política, pues ideológicamente la universalización de la educación, no solo primaria, sino secundaria, es un elemento fundamental de la igualdad social.

Así, la trayectoria de la política de educación secundaria en Andalucía se inicia en 1985 con el objetivo de extender la prestación de los servicios, construyendo más colegios públicos e incrementando la dotación de personal y medios materiales. Para afrontar, primero, el incremento de alumnos de los años 80, segundo, la extensión de la edad de educación obligatoria y, tercero, el incremento de los servicios de atención a los alumnos con dificultades y la diversidad, introducida en la década de 1990 con la LOGSE.

Esta situación hace que haya habido una trayectoria ininterrumpida en la política, con estabilidad y permanencia en cuanto a la definición de los problemas públicos y poca ambigüedad en las soluciones planteadas, así como un control casi absoluto de la agenda gubernamental por parte del PSOE-A. La definición de objetivos ha reflejado los valores e ideología predominantes del PSOE-A. Entre ellos destaca, antes de 2006, la preferencia por la gestión pública directa a los conciertos con colegios privados. No obstante, la LOGSE en 1990 estableció los conciertos, particularmente con colegios religiosos católicos, como una forma de asegurar un derecho de libre elección de valores por parte de los padres, por lo que la Junta de Andalucía debía respetarlos.

Para cumplir con la LOGSE, promulgada por un gobierno socialista en el Estado central, el PSOE-A firmó conciertos con colegios privados, integrándolos en el sistema público como servicios externalizados. En Andalucía la mayoría de los colegios privados deseaban firmar conciertos con la Junta a principios de los años 90, por lo que se incorporó al sistema público alrededor de un $25 \%$ más de oferta de plazas sobre las que tenían los institutos públicos. Así, se llegó a una proporción 80 / 20 \% entre institutos de gestión directa y centros concertados. Este balance ha permanecido inalterado hasta 2006, siendo un elemento del equilibrio de la trayectoria del subsistema andaluz.

Hay que tener en cuenta que los colegios privados cubren la demanda de las zonas urbanas de mayor nivel de renta, aunque también está presente en zonas urbanas antiguas o históricas con niveles menos altos de renta. Sin embargo, ha sido el sector público gestionado directamente el que se ha encargado de llegar a las zonas más deprimidas, en las que se debían aplicar mayores recursos de refuerzo a partir de la LOGSE.

En este punto podemos establecer que el segundo gran objetivo de la educación secundaria en Andalucía, antes de 2006, ha sido la equidad. Este objetivo se planteó también como un valor ideológico del PSOE-A, que pretendió dar oportunidades a los jóvenes de las zonas con menos nivel de renta a través de su promoción en el sistema educativo.

La conjunción de la predilección por la gestión directa y la equidad en las zonas de menos renta se ha plasmado en que la Comunidad andaluza apenas financia a los colegios concertados más allá de las matrículas de los alumnos y del salario de sus profesores, aunque en este sentido hay que señalar que el Gobierno andaluz ha favorecido las demandas salariales de los profesores de colegios concertados, acercándolas a las de los profesores del sector público.

Además, la Consejería de Educación ha mantenido un control sobre los institutos de enseñanza secundaria a través de un contacto continuo con los directores, de la transferencia de recursos económicos, materiales y personales, como los profesores de refuerzo, y de la asistencia de los inspectores de educación a los centros. Esto no ha anulado el papel de los consejos escolares, pero hay que tener en cuenta que en estos consejos estaban presentes asociaciones de padres y madres de alumnos (AMPAS) junto al claustro de profesores y estudiantes. Como se reflejó en las entrevistas realizadas, las AMPAS mayoritarias en los centros públicos andaluces han compartido valores y objetivos estratégicos con la izquierda política. Tampoco los sindicatos parecen haber discutido las bases del modelo educativo andaluz, ni el control de la Consejería sobre los centros públicos, así que los Consejos Escolares no han sido foros que hayan reivindicado proyectos educativos propios para sus institutos.

En suma, Andalucía ha configurado un modelo educativo con predominio de la gestión directa, y centralización administrativa de la gestión y control de los institutos de secundaria, en el que el criterio de adscripción principal en la selección de los alumnos es su lugar de residencia. Junto a este modelo coexiste una red de colegios concertados, que tienen más capacidad para seleccionar a su alumnado, aunque la Consejería de Educación mantiene también un control sobre estos aspectos, obligándoles a cumplir los criterios zonales o impidiendo la segregación de género, por ejemplo.

10 Ha gobernado ininterrumpidamente desde la fundación de la Comunidad en 1982. Desde 2012 gobierna por primera vez en coalición con Izquierda Unida-Convocatoria por Andalucía (IU-CA), pues los socialistas no tienen mayoría absoluta en el Parlamento andaluz, situación que solo se había dado previamente entre 1994 y 1996, periodo en el que gobernó con mayoría relativa. 
Los elementos clave de este modelo han permanecido con la publicación en 2006 de la LOE. No obstante, el Gobierno andaluz aprovechó la oportunidad para redefinir la política de educación, particularmente la de secundaria obligatoria. La extensión de la red de centros hacía tiempo que estaba completada, y se les había dotado de personal y medios. Pero la LOE supuso en Andalucía un impacto sobre la trayectoria, percibido no tanto como un suceso dramático, sino como una oportunidad.

En el ámbito andaluz la LOE supuso repensar los problemas, iniciando la corriente de problemas y buscando referencias y alternativas en la corriente de las políticas públicas, que dado el entorno de actores del subsistema andaluz, tendían a encajar plenamente en la ideología del PSOE-A. Así, a priori, el caso andaluz es la apertura de una ventana de políticas casi perfecta, coincidiendo las tres corrientes en 2007 para producir un cambio de trayectoria en la política de educación secundaria de Andalucía.

En aquel momento, tanto el Gobierno andaluz como los actores sociales más relevantes, tales como AMPAS, sindicatos y partidos políticos, coincidían en que Andalucía tenía dos problemas públicos en la educación secundaria, que estaban ligados entre sí: el abandono y el fracaso escolar.

El abandono escolar era un fenómeno que existía en Andalucía con anterioridad al traspaso de la competencia, ya que, tradicionalmente, en las zonas rurales los padres reclamaban a sus hijos a edades tempranas para trabajar. Así, muchos jóvenes andaluces no terminaban sus estudios. Con el crecimiento económico producido desde la segunda mitad de los años 90 hasta 2008, el fenómeno del abandono se ha vinculado a la facilidad que tenían los jóvenes de encontrar empleo en el sector de la construcción, dejando el sistema educativo sin acabar la educación obligatoria, al igual que habían hecho sus padres.

Junto a este fenómeno de abandono está el fracaso escolar, la falta de superación de los requisitos mínimos para permanecer en el sistema educativo. La LOGSE había flexibilizado los criterios para que los alumnos superaran los cursos, aunque tuvieran que aprobar todas las asignaturas para superar el paso de un ciclo educativo a otro. De hecho, era el claustro de profesores de cada centro el que establecía el paso de un curso a otro o de un ciclo a otro, y por tanto en la práctica, el que facilitaba o no la obtención de títulos académicos. En este claustro de profesores de cada centro suelen participar de alguna forma los inspectores de educación. La mayor parte de los casos de fracaso escolar en Andalucía suelen acabar en abandono, por lo que este problema se redirige al anterior, aunque los actores sociales señalan que existe un nivel alto de alumnos con bajo rendimiento académico, que repiten cursos antes de abandonar el sistema educativo.

Para solucionar estos dos problemas, el Gobierno andaluz rediseñó su política educativa en 2007 a través de la Ley de Educación de Andalucía (LEA), que establece como objetivos eliminar el abandono y mejorar el rendimiento de los alumnos. La LEA ha sido una iniciativa del propio Gobierno andaluz, en cuyo anteproyecto incorporó la visión de los sindicatos entonces mayoritarios, UGT y CC.OO., con una ideología similar a la del PSOE-A, a través de la Mesa de Concertación. También los responsables políticos escucharon al Consejo Escolar de Andalucía, en donde están representados los estudiantes, las AMPAS y las patronales del sector privado concertado, y la Asociación de Directores de Colegios Públicos de Educación Secundaria. En cada sector el PSOE-A tuvo más en consideración a las organizaciones más afines, por ejemplo, a la patronal de las cooperativas de profesores, ACES, cuyos colegios están concertados en su mayoría, frente a Escuelas Católicas, organización patronal conservadora que tiene muchos más colegios concertados.

La participación del conjunto de actores sociales del área de educación secundaria se produjo también en la Comisión Parlamentaria que tramitó y elaboró el texto definitivo. En esta Comisión comparecieron casi todos los actores relevantes, aunque sin voto. El Parlamento andaluz finalmente aprobó la LEA con los votos del PSOE-A, que tenía mayoría absoluta y de IU, que entonces no gobernaba junto al PSOE-A. En contra votó el PP.

Sin embargo, pese a que se pueda considerar que la LEA marca una interrupción del anterior equilibrio en la educación andaluza, los programas desarrollados a partir de la LEA para solucionar los problemas públicos planteados en la educación secundaria obligatoria se pueden considerar como incrementalistas respecto a la situación previa a 2007.

Respecto al fracaso escolar se han elaborado programas que incrementan las estrategias y los medios establecidos en su día por la LOGSE: personalización para los alumnos con especiales dificultades con clases de apoyo y refuerzo; incremento de la oferta de itinerarios curriculares, o la promoción del uso de las nuevas tecnologías como medio para integrar a los jóvenes en el sistema educativo, por ejemplo. 
Como en otras comunidades autónomas, también se han desarrollado programas co-financiados y diseñados por el Ministerio de Educación, como Aula 2.0, que pretendía incorporar pizarras digitales y acceso a internet en las aulas, o el programa de entrega de ordenadores portátiles básicos a los alumnos de secundaria ${ }^{11}$.

Para tratar el abandono, el Gobierno andaluz ha sido más innovador, pues además de los programas que inciden en reducir el fracaso, se planteó un programa específico nuevo, “Beca 6000”, por el que se paga 600 euros al mes en los meses lectivos a alumnos con buen rendimiento académico que vivan en zonas de bajas rentas y cuyas familias les reclamen entrar en el mercado laboral.

No obstante, todos estos programas tienen como objetivo, no sólo impedir el abandono, sino en última instancia la equidad social, uno de los objetivos fundamentales del subsistema educativo andaluz desde 1982, por lo que podemos considerar que estos programas lo que hacen no es interrumpir el equilibrio previo de la trayectoria de la política, sino continuarla de forma incremental.

También hay que destacar de la LEA que fija el status de colegios concertados de manera continuista, permitiendo la prórroga de los conciertos existentes cada cuatro años, pero estableciendo que en el caso de que la demanda de alumnos en una determinada zona baje, se dejará de renovar el concierto, pasando los alumnos al colegio público más cercano o eligiendo uno privado fuera del ámbito público. Esto llevó en 2012 a que el balance de colegios concertados sobre el total de la oferta pública de plazas de educación secundaria obligatoria haya bajado del 20 al $18 \%$.

En suma, el Gobierno andaluz ha utilizado el marco de la LOE para dar un paso incremental en su modelo educativo. Pese a abrir de forma explícita un proceso de reformulación de la política pública educativa a través de la elaboración de una Ley autonómica, el resultado final ha sido un reforzamiento de la trayectoria de la política que venía haciendo el Gobierno andaluz. Hay que tener en cuenta que este modelo ha desarrollado claramente los valores del PSOE-A, reflejando los efectos de su posición como partido predominante en el sistema de partidos de Andalucía. En este sentido hay que destacar que la educación, tanto primaria como secundaria, es una prioridad creciente para el PSOE-A, y ha sido una de las áreas que menos recortes presupuestarios ha sufrido desde 2011.

En Andalucía podemos observar como bajo la apariencia de interrupción del equilibrio (True, Jones y Baumgartner, 1999) se esconde un simple incrementalismo (Lindblom, 1979). El problema de la educación secundaria entró en la agenda gubernamental por la iniciativa del propio Gobierno andaluz y el PSOE-A, en torno al cual han girado los sindicatos, AMPAS, la asociación de directores de escuelas de secundaria, la de inspectores, etc., incluso IU-CA. Todos estos actores formaron una coalición estable que, aun teniendo discrepancias y conflictos, comparten los valores e ideología y las prioridades y alternativas sobre la política, y son los que participan e impulsan la corriente de las políticas. Las alternativas que proponen ya están limitadas por razones ideológicas, son incrementales, y por eso encajan perfectamente en la corriente de la política, limitando el impacto innovador que la LOE en 2006 podía haber tenido en la corriente de los problemas, que aunque se redefinen, mantienen una clara continuidad. Esta continuidad se refleja en el mantenimiento del control de la gestión de los institutos, en el equilibrio entre centros de gestión directa y concertados, en la aplicación de los procedimientos de promoción de alumnos y en los procedimientos de asignación de alumnos a los centros.

\section{LA COMUNIDAD DE MADRID: LA VISIÓN ECONÓMICA}

En el caso de la Comunidad de Madrid, su punto de partida es claramente diferente de las otras dos comunidades autónomas, ya que recibió las competencias en educación no universitaria en 1999 y 2000 . Esto implica que todo el desarrollo y ejecución de leyes marco del Estado central, como la LODE y la LOGSE, en el territorio de la Comunidad de Madrid le ha correspondido a la Dirección Provincial del Ministerio de Educación hasta el año 2000. El Ministerio no definió ningún tipo de problema público, ni objetivo específico para Madrid, ni para ninguna otra Comunidad Autónoma en la que mantuviera la gestión hasta el 2000, por lo que no había una trayectoria clara de la política educativa para Madrid en el momento del traspaso.

Así, en el caso de la Comunidad de Madrid el modelo educativo se pudo definir de manera específica a partir del 2000, pero en el primer momento de ejercicio de la competencia, la preocupación principal de los responsables políticos autonómicos parecía ser la asunción del traspaso sin grandes cuestionamientos de la situación previa. Hay que recordar que el Gobierno autonómico madrileño está en manos del PP desde 1995 hasta hoy con mayoría absoluta. En 1999 y 2000, el PP también tenía mayoría y el Gobierno en el Estado central, que conservó hasta 2004.

11 La falta de financiación del Ministerio en la actualidad está obligando a eliminar algunos de estos programas. 
En ese contexto, el traspaso de los medios personales de la Dirección Provincial incluyó mantener al personal directivo en los primeros momentos.

Además, a partir del año 2000 las autoridades educativas madrileñas tenían la expectativa de la entrada en vigor de la LOCE, que se publicó en 2002, y que finalmente no entró en vigor. Esta Ley hubiera abierto la ventana en la corriente de la política para definir un modelo que desarrollara de manera explícita los postulados y valores del PP en el ámbito autonómico. Sus postulados estaban vinculados, en el apartado de la gestión, a dar mayor peso a los colegios concertados y a la introducción de la religión católica como asignatura evaluable en la parte de currículo competencia del Estado central. Sin embargo, al no entrar en vigor la LOCE, la Comunidad de Madrid comenzó a desarrollar en el ámbito autonómico postulados semejantes en la parte competencial que le correspondía, pero sin formularlos de forma explícita en una Ley autonómica o a través de un debate público. No obstante, en 2006 con la LOE surgió una nueva oportunidad para definir el modelo de política de educación secundaria de la Comunidad de Madrid, ya que esta Ley, al dejar un margen de decisión autonómico, facilitaba que los valores del PP de Madrid se desarrollaran plenamente, particularmente en cuanto a la gestión de los centros, la selección del alumnado y la gestión de los recursos humanos.

Hay que tener en cuenta que la Comunidad de Madrid venía desarrollando desde 2003, que llegó, a la Presidencia autonómica Esperanza Aguirre (2003-2012) una práctica que afectaba profundamente al modelo educativo, aunque aparentemente no reformulaba la política educativa.

Hasta 2003, en las zonas recién urbanizadas la Comunidad de Madrid construía colegios públicos de educación primaria y de secundaria, al margen de que concediera también licencias para construir colegios privados que iban a ser concertados, pero con una densidad menor que de institutos públicos. En la práctica esto permitía cierta capacidad de elección a los padres para matricular a sus hijos en las zonas recién urbanizadas. Hay que recordar que desde 1995 gobernaba el PP en la Comunidad de Madrid, y ese periodo coincidió con una enorme expansión inmobiliaria y el desarrollo de muchas nuevas zonas urbanas, con un fuerte crecimiento demográfico, pasando la población regional de 5 millones a 6,5 entre 1995 y 2012.

A partir de 2003 la Comunidad de Madrid comenzó a firmar convenios para los nuevos desarrollos urbanosque incluían la financiación y construcción de los colegios de primaria y secundaria por parte de entidades privadas, a cambio de la cesión durante 75 años del suelo público que estaba reservado para edificar los equipamientos educativos públicos, y de que los colegios fueran concertados, con la condición de que no se construyera ningún otro centro público, ni privado concertado en la misma zona, por lo que no hay competencia.

Otra práctica reseñable del Gobierno madrileño es que, a diferencia de Andalucía, no ha intervenido para que los salarios de los profesores de los centros concertados sean semejantes a los de los centros públicos, por lo que su salario es menor y esa diferencia salarial se la ahorra la Comunidad, que es la que abona los mismos.

La red de centros privados concertados en Madrid ya era amplia, y muy asentada en las áreas centrales de la ciudad de Madrid y otras grandes ciudades de la región. La mayor parte de estos convenios los había firmado el Ministerio de Educación antes del traspaso y suponían algo más de un tercio del total de la oferta de plazas educativas en el año 2000. En la actualidad se ha superado el 50\% de oferta externalizada sobre la de los centros de gestión directa en el total de la educación obligatoria, tanto de primaria como de secundaria.

Así, desde 2003 se puede entender que existe un objetivo de ahorro de costes en el Gobierno autonómico, o incluso de eficiencia a corto plazo, que nos permite identificar que los dirigentes de la educación madrileña han definido un problema de costes o de ineficiencia de la prestación de los servicios educativos, más que un problema educativo en si. No obstante, hay que destacar que esta práctica ha finalizado desde 2009, a causa de que la crisis económica ha impedido que se concedan los créditos bancarios con los que se realizaban estos proyectos.

Podemos ver con este tipo de actuaciones que un elemento clave del equilibrio del subsistema educativo madrileño es el reparto del alumnado entre centros concertados y públicos. Un segundo elemento que podemos identificar es que existe una tensión en el subsistema entre los sindicatos y el Gobierno autonómico.

A partir de 2006, la LOE ha supuesto nuevos elementos en el modelo, que han ido apareciendo como programas parciales, y no como un plan general de la política. Sin embargo, si los analizamos en conjunto podemos ver que tienen un objetivo y valores comunes.

Entre los programas que podemos destacar en la educación secundaria madrileña desde 2006 están el programa de bilingüismo, inglés y castellano, el programa de excelencia educativa y la separación en distintos centros entre Bachillerato y Formación Profesional en la secundaria no obligatoria. Todos tienen un objetivo común, 
buscan mejorar el acceso al mercado laboral de los alumnos de educación secundaria. Lógicamente, esto implica la definición de un problema público de falta de adecuación de los alumnos a las necesidades de las empresas (Antón, 2009). También implica un intento por introducir criterios más estrictos de promoción de los alumnos, en línea inversa a los que planteó la LOGSE, y en consonancia con lo que preveía la LOCE.

No obstante, los resultados de estos programas están siendo muy discutidos en los medios por los actores sociales opuestos a esta política. Por un lado, los programas citados han sufrido recortes en los presupuestos con la crisis económica. Por otro lado, sus resultados son limitados. Por ejemplo, el programa de excelencia, que busca clasificar y formar grupos separados de alumnos según su rendimiento en cada centro ( $A, B, C, D)$, y que los mejores de toda la Comunidad finalmente acudan a colegios de excelencia separados, todavía no se aplica en muchos centros, pues cuenta con el rechazo de muchos alumnos. El programa de bilingüismo está extendido a la mayoría de los institutos públicos y muchos de los privados concertados, pero se cuestiona que realmente los profesores españoles impartan sus asignaturas en inglés ${ }^{12}$.

Otro aspecto relevante es que estos programas se extienden por igual al sector privado concertado y al sector de gestión directa, como también ocurre con los programas de asistencia para alumnos con problemas o necesidades de apoyo, que en principio eran los que la LOGSE preveía para las zonas de menor renta o para las familias con menos recursos. En este punto hay que señalar que los colegios concertados, particularmente los que tenían conciertos anteriores a 2003, tienen autonomía para seleccionar a los alumnos que admiten, aun teniendo en cuenta los criterios de la Comunidad. Los centros concertados posteriores a 2003 se han asentado en zonas con rentas medias altas y altas, por lo que no necesitan filtrar. En conclusión, la mayoría de los alumnos de familias con menos renta estudian en colegios con gestión directa, y aunque existen colegios concertados cuya selección se enfoca a los alumnos de menor renta, la mayoría de estos centros prefieren alumnos de clases medias altas.

Podemos caracterizar el modelo de educación secundaria madrileño por la orientación al mercado en la provisión del servicio y en el tipo de alumnos que busca titular, y por el fomento de la competencia entre los propios alumnos. Es un modelo que busca la eficiencia económica por encima de la integración de los actores sociales, y esto se puede constatar, como han indicado varios actores sociales en sus entrevistas y demuestran las actas del Consejo Escolar de la Comunidad de Madrid, en el reducido papel que se le da a éste en la práctica, o a los consejos escolares de los institutos. También se puede identificar con el enfrentamiento constante con los sindicatos, incluso con algunos con los que no tendría un enfrentamiento ideológico, como el CSI-F.

Otra característica del modelo es que tiende a dar una cierta autonomía de gestión a los institutos públicos. Estos centros pueden decidir adoptar programas clave, como el bilingüismo o el de excelencia, aunque pierdan con ello los recursos que conlleva. También pueden optar por ofrecer ciertas asignaturas optativas, si identifican una demanda específica más allá de su zona de cobertura. En definitiva, tienen cierta capacidad para tomar decisiones, teniendo en cuenta que la Consejería de Educación también fomenta la competencia entre centros, aportando más recursos a los que consigan mejores ratios en diferentes tipos de indicadores de rendimiento de los alumnos.

No obstante, conviene destacar que la educación secundaria no parece ser una prioridad para el Gobierno de la Comunidad de Madrid, frente a otros temas de agenda como los urbanísticos o los fiscales. Esto no hace que no exista una corriente de la política para este tema, existe y en la misma se pueden identificar los postulados ideológicos del Partido Popular de Madrid, vinculados a una visión en la que priman la competencia, el predominio del sector privado y la preocupación por el rendimiento económico. Además, también tenemos una corriente de problemas, ya que los sucesos y demandas sociales hacen que el tema se convierta en problema público continuamente, cierto que con la ambigüedad de las diferentes definiciones del mismo. En todo caso se han abierto ventanas tanto en la corriente de la política y de los problemas entre 2007 y 2011, en la que también ha coincidido una corriente de las políticas públicas, a través de medios de comunicación, actores sociales afines al PP de Madrid y expertos relacionados con la elaboración de la fallida LOCE, que han aportado opciones y alternativas orientadas al rendimiento económico.

A pesar de la apertura de las ventanas, la Comunidad de Madrid ha desarrollado una trayectoria de la política cuyo equilibrio no ha sido totalmente interrumpido, sino que se ha aprovechado para incrementar y avanzar en la misma línea. Además, el subsistema autonómico está asentado, ya que el Gobierno de la Comunidad de Madrid

12 La Consejería está tratando de incorporar profesores de países anglo-parlamentes para impartir asignaturas no lingüísticas, lo que implica el reconocimiento de que no ha conseguido sus objetivos, pero de momento el Ministerio de Educación no lo permite por ir en contra de los criterios de selección del profesorado, tanto en los colegios de gestión directa como en los privados con acuerdo. 
tiene un conjunto de actores aliados, como determinados sectores de la Iglesia Católica, AMPAS católicas, patronales de escuelas concertadas, y deja en frente a los sindicatos de todo signo ideológico.

\section{CONCLUSIONES}

Si comparamos estos tres casos, podemos ver algunos elementos relevantes:

- Cada uno de ellos han desarrollado modelos con objetivos diferentes, definidos a nivel autonómico por sus responsables políticos.

- A la hora de definir sus objetivos, cada gobierno autonómico ha primado los criterios ideológicos. En los dos casos en que el modelo de educación secundaria autonómico lo ha desarrollado un partido con mayoría absoluta, estos objetivos responden claramente a los valores de sus dirigentes y sus partidos a nivel autonómico. En el caso en el que han predominado los gobiernos de coalición, se ha creado un modelo más consensuado, aunque no exento de tensiones.

- Los gobiernos autonómicos también responden a situaciones específicas de sus sociedades y sus entornos que son claramente diferentes en cada caso, situaciones y demandas que eran diferentes antes del traspaso de la competencia. En este sentido, las comunidades autónomas demuestran su adaptación y cercanía a problemas concretos.

- La promoción de las políticas, con la definición de problemas y objetivos, ha partido de los dirigentes gubernamentales en los tres casos, y en los cambios de cada uno.

- Dado que la iniciativa ha sido gubernamental, el asentamiento en la agenda gubernamental ha estado muy controlada.

- Contrasta en los casos vasco y andaluz que, con la publicación de la LOE en 2006, el primero pretende ser incrementalista, pero esconde cambios profundos o rupturas de la política. Andalucía por el contrario, ha elaborado su propia ley para plantear cambios profundos en su política, pero hay más incrementalismo de lo que parece. En el caso madrileño la LOE es directamente una oportunidad para intensificar las características de su modelo.

En suma, si miramos las tres preguntas que nos formulamos inicialmente con respecto a estas tres comunidades autónomas, la primera de ellas - ¿por qué se definieron diferentes modelos si el marco general del Estado es el mismo? - la respuesta es que han hecho así porque responden a muy diversos ambientes sociales, que les hace desarrollar diferentes respuestas a diferentes problemas públicos. La ventana de oportunidades derivadas de los problemas actuales (Zahariadis, 1999) es específica para cada comunidad autónoma, aunque puede ser abierta debido a los cambios en la legislación estatal. Por lo tanto, la jurisdicción autónoma de educación secundaria ha cumplido su objetivo de adaptar las políticas de ambientes sociales y la respuesta a la pregunta: "¿Se adaptan a las diferentes situaciones de cada comunidad autónoma?" es afirmativa, también.

La contestación a la pregunta "¿Qué criterios siguen las distintas comunidades autónomas para definir sus políticas?" es la ideología de los partidos gobernantes, que permite la identificación clara de las decisiones de los votantes, pero también implica mayores tensiones y disputas en las políticas educativas, puesto que la falta de acuerdo entre las partes hace que se interrumpa la trayectoria de la política cuando se producen cambios de partido gubernamental, así como ocurre en el Estado central. Son los partidos de gobierno los que más influyen en las corrientes políticas y permiten identificar cuando se abre una ventana de oportunidad política (Zahariadis, 1999).

“¿Se integra en los procesos de definición de los problemas y los objetivos a los actores sociales?” La respuesta es que los actores sociales participan formalmente en los consejos escolares de las distintas comunidades autónomas, pero también tienen relaciones informales con los actores gubernamentales. Sin embargo, los sectores sociales que ideológicamente están más relacionados con los partidos gobernantes tienen más relaciones informales y una mayor influencia en las políticas de cada comunidad analizada.

Además de estos hallazgos que podemos considerar sistémicos, que muestran como los gobiernos autonómicos utilizan su capacidad para tomar decisiones estratégicas en una materia concreta, la comparación de los casos nos permite llegar a algunas conclusiones respecto a las políticas de educación autonómicas.

Un elemento especialmente relevante que podemos comparar es la autonomía de los centros educativos, objetivo de los sucesivos marcos legales estatales desde 1970 (Hanson 1994; Bolívar, 2004b; Madera, Martín y Pérez, 2014). Esta autonomía se vinculó, en la LODE (1985), a la creación del Consejo Escolar, encomendándole al 
mismo en la LOGSE (1990) la definición de un proyecto educativo en el centro y la elección del director del mismo. Este incremento de funciones también incluía la posibilidad de que los institutos públicos asumieran mejoras en su gestión interna por si mismos, al igual que hacían algunos centros privados concertados. Esta posibilidad de dotar de autonomía a los institutos públicos de educación secundaria debía haber sido impulsada e implementada por las comunidades que tenían traspasada la competencia, como Andalucía y País Vasco, y Madrid desde el 2001.

En el caso andaluz, la autonomía de los centros es un aspecto que se desarrolló poco. Los sucesivos gobiernos andaluces previos a la LOE implementaron el marco legislativo estatal sin impulsar la autonomía de los centros educativos públicos para diseñar un proyecto educativo propio o medidas de calidad en la gestión. Tampoco se impulsó esta capacidad en el caso madrileño antes de 2006. Sin embargo, en el caso vasco sí se impulsó alguna autonomía en los centros públicos, aunque los proyectos educativos que desarrollaron los centros públicos estaban derivados del modelo lingüístico que elegían los padres. No obstante, esta capacidad de elección se trasladó a la mayoría de los programas y proyectos pedagógicos propios, al igual que los concertados, y orientar el centro hacia cierto tipo de estudios. Es una diferencia esencial con el caso andaluz, en el que la Consejería implantaba en la práctica los programas en todos los centros públicos o, en su caso, decidía en cuáles los implantaba. Con todo, hay que señalar que esta pequeña autonomía de los institutos públicos vascos no era una decisión expresa del Gobierno vasco, sino el resultado a lo largo del tiempo de los acuerdos políticos de las coaliciones, que dejaban que los programas fueran optativos para los centros, tanto públicos como concertados, para no entrar en conflicto entre ellos. En el caso madrileño todavía hay que ver si esta autonomía se desarrolla.

A partir de 2006 la LOE convirtió la posibilidad de que los centros educativos públicos pudieran desarrollar su propio proyecto educativo y de gestión en un mandato, aunque eran las comunidades autónomas las que debían desarrollar y precisar el contenido de estos proyectos educativos que los centros de enseñanza secundaria debían presentarles. Al llegar el tema de la autonomía de los centros a los subsistemas políticos autonómicos, con los traspasos, lo ha hecho sin una clara prioridad. A pesar de que la gestión de los centros es una de las funciones más importantes traspasadas a las CC.AA., en ninguno de los tres casos analizados se encuentra este tema como prioritario, ni tampoco la introducción de herramientas de gestión calidad en el conjunto del sistema educativo. Los proyectos educativos y la calidad de la gestión de los centros de enseñanza son temas de la corriente de las políticas, que provienen de los informes de los expertos, (Hanson, 1994; Bolívar, 2004b) y que no encuentran abiertas las ventanas en la corriente de problemas, ya que no se identifican como problemas públicos, y tampoco están claros los valores ideológicos que podrían encajar en la corriente de la política. Son temas que llegan a formularse, en el sentido que se recogen en la legislación (Madera, Martín y Pérez, 2014; 289) pero que no se llegan a implementar en la práctica, básicamente porque las consejerías, y antes el Ministerio, controlan con multitud de normativas administrativas las acciones de los centros (Hanson, 1994; Bolívar, 2004b).

En los tres comunidades autónomas analizadas, la corriente de los problemas ha ido definiendo asuntos diferentes. En el caso del País Vasco se ha definido como problema público fundamental el lingüístico, resultado de un conflicto social que está más allá de la educación secundaria y es un tema que siempre encuentra coincidencia con la corriente de la política en el sistema político vasco, ya que la ventana de este último está permanentemente abierta.

En el caso de Andalucía se han definido como problemas públicos el abandono y el fracaso escolar, dos caras de un mismo asunto. La ventana de la corriente de los problemas coincidió con la ventana de la política, en tanto que entró en el programa de los partidos políticos andaluces, y que es un tema de especial relevancia social (Zahariadis, 1999) y una oportunidad para el partido de gobierno.

En el caso de la Comunidad de Madrid la ventana de la corriente de problemas se abrió doblemente, por un lado con la necesidad de extender la oferta de centros con un bajo coste, y por otro lado con la necesidad de adaptar el modelo educativo a las demandas productivas. En este caso, la ventana de la política la define el partido de gobierno, que la abre como oportunidad de cambiar el modelo heredado del Estado central.

En los tres casos se han abierto al tiempo las ventanas de las corrientes de problemas y de políticas para que cada Comunidad Autónoma haya definido su política de forma diferente. Sin embargo, no se ha abierto la ventana de la política pública para los temas y políticas que han desarrollado. Aunque lo fundamental es la apertura simultánea de las ventanas de oportunidades de las corrientes de problemas y de política (Zahariadis, 1999).

Junto a la autonomía de los centros, otro elemento que han ido configurando los modelos educativos es el papel de los actores sociales involucrados en la educación. Los tres casos expuestos tienen en común el impulso de las políticas por parte de los respectivos gobiernos, que asumen el rol de director (Dente y Subirats, 2014:123). 
Esto no significa que los actores sociales no tengan papel en los tres subsistemas autonómicos, pero sí que este es el de apoyo o no a la acción gubernamental, con una notable excepción en los tres casos: los partidos políticos de gobierno, que tienen el papel de promotor de la política (Dente y Subirats, 2014:122). El resto de los actores, como AMPAS, asociaciones de estudiantes, sindicatos y patronales, tienen más o menos influencia en la política en la medida en que están en sintonía con los partidos gubernamentales, asumiendo roles de aliados u opositores (Dente y Subirats, 2014:126). El recurso fundamental que aportan los actores sociales en los tres análisis es el de apoyo social y, en su caso, la movilización.

En el País Vasco, la relevancia de los actores sociales que no son partidos es mayor, como consecuencia de que los partidos gubernamentales no tienen mayorías absolutas, y el recurso de apoyo social y consenso político es más relevante. En el caso andaluz los actores sociales también han aportado sus recursos de consenso, los aliados, o disenso, los opositores, alineándose estos actores sociales en un claro eje político a la izquierda o a la derecha. En el caso madrileño, el gobierno y el PP de Madrid han considerado menos necesario el recurso del apoyo social, aunque esto no ha evitado que los actores sociales hayan asumido sus roles de aliados u opositores, siendo estos últimos el conjunto de los sindicatos, y las AMPAS y asociaciones estudiantiles que podemos considerar laicas.

En resumen, vemos como bajo el mismo marco legal se configuran modelos educativos diferentes, con subsistemas de políticas educativas distintos, que responden cada uno a sus prioridades, aunque en todos los casos éstas están definidas por los partidos de gobierno.

\section{BIBLIOGRAFÍA}

Antón, A. (2009) Políticas educativas ante la crisis. Madrid: Fundación $1^{\circ}$ de mayo.

Barzelay, M. y R. Gallego

- (2006) “From 'New Institutionalism' to 'Institutional Processualism': Advancing Knowledge about Public Management Policy Change”, en: Governance, vol. 23, n² 2, pp. 209-223. DOI: 10.1111/j.14680491.2006.00339.x.

- (2010) "The Comparative Historical Analysis of Public Management. Policy Cycles in France, Italy and Spain: Symposium Introduction”, en: Governance, vol. 23, n² 2, pp. 209-223. DOI: 10.1111/j.1468-0491.2010.01476.x

Baumgartner, F. R., y Jones B. J. (1993) Agendas and Instability in American Politics. Chicago: TheUniversity of Chicago Press. DOI: 10.5860/choice.31-0574.

Beltrán Llavador, J.; Hernández Dobon, F.; Montané López, A. (2008) Tradición y modernidad en las políticas educativas en España: una revisión de las últimas décadas, en: Revista Iberoamericana de Educación (OEI), 2008, num. 48, p. 53- 71.

Boix, M., y García Suárez J. A. (1985) La LODE. Anàlisi i comentaris desde Catalunya a una llei controvertida. Barcelona: Universidad de Barcelona.

Bolívar, A. (2004a) "La educación secundaria obligatoria en España. En la búsqueda de una inestable identidad”, en: Revista Electrónica Iberoamericana sobre Calidad, Eficacia y Cambio en Educación (REICE), vol. 2, nº 1 (Disponible en: http://www.ice.deusto.es/RINACE/reice/vol2n1/Bolivar.pdf).

Bolívar, A. (2004b): "La autonomía de centros escolares en España: entre declaraciones discursivas y prácticas sobrerreguladas”, en: Revista de educación, n³33, pp. 91-116 (enero-abril) http://www.revistaeducacion.mec. es/re333.htm

Bonal, X. (2002) “El balance público-privado en el sistema de enseñanza español: evolución y efectos sobre las desigualdades educativas”, en: Educar, n²9, pp. 11-29.

Bonal, X. (2011) Descentralización de la política educativa: balance y perspectivas de futuro. Ponencia presentada en el I Seminario sobre educación y políticas educativas en España, Madrid, 15-17 de noviembre de 2011.

Bozal, V., y Paramio L. (1975) La enseñanza en España. Madrid: Comunicación.

Dente, B. y Subirats, J. (2014): Análisis y estudio de los procesos de decisión en políticas públicas. Barcelona: Ariel. DOI: 10.17141/iconos.53.2015.1847.

Fullan, M. (2002) Los nuevos significados del cambio en educación. Barcelona: Octaedro.

Gómez Llorente, L. (1983) “La política educativa”, en: Cuadernos de Pedagogía, n 100. pp. 77-81. 
Hanson, E. (1994). “Democracy, Decentralization and School-Based Management in Spain”, en: La Educación, Vol. 38, N², pp. 319-334.

Kingdon, J. W. (1995) Agendas, Alternatives and Public Policies ( $2^{\mathrm{a}}$ ed.). New York: Harper Collins College Publishers ( $1^{\circ}$ ed. 1984$)$.

Lindblom, C. (1979) “Still Muddling, not yet through”, en: Public Administration Review, vol. 39, n 6, pp. 517526. DOI: $10.2307 / 976178$.

Madera, E.; Martín, P.; y Pérez, L. (2013) “Políticas Públicas de las Comunidades Autónomas. Descentralización y Servicios de Bienestar”, en: Ferri, Jaime (ed.) Política y Gobierno en el Estado autonómico, Tirant lo Blanc, Valencia, pp. 269-309.

Subirats, M. (1975) “Los primeros cuatro años de la Ley General de Educación”, en: Cuadernos de Pedagogía, vol. 1, pp. 2-5.

True, J. L., Jones, B. D. and Baumgartner, F. R. (1999) "Punctuated-Equilibrium Theory: Explaining Stability and Change in American Policymaking”, en: Sabatier, P. (ed.) Theories of the policy process. Boulder (Colorado): Westview Press. pp. 97-116.

True, J. L., Jones, B. D. and Baumgartner, F. R. (2007) "Punctuated-Equilibrium Theory: Explaining Stability and Change in American Policymaking”, en: Sabatier, Paul (ed.) Theories of the policy process ( $2^{\text {a }}$ ed.).Boulder (Colorado): Westview Press, pp. 155-187.

Tyack, D. y Cuban, L. (2000) “En busca de la Utopía”, en: autor Un siglo de reformas en las escuelas públicas. México: FCE/SEP.

Zahariadis, N. (1999) “Ambiguity, Time and Multiple Streams”, en Sabatier, Paul (ed.) Theories of the Policy Process. Boulder (Colorado): Westview Press, pp. 73-93.

Zahariadis, N. (2007) “Ambiguity, Time and Multiple Streams”, en Sabatier, Paul (ed.) Theories of the Policy Process. ( $2^{\mathrm{a}}$ ed.) Boulder (Colorado): Westview Press, pp. 65-92.

\section{Fuentes documentales consultadas:}

Consejo Escolar de Andalucía (2010) Informe sobre el estado y situación del sistema educativo de Andalucía 2007-08, 2008-09, Sevilla, Consejería de Educación de Andalucía.

Consejo Escolar de Andalucía (2008) Informe sobre el estado y situación del sistema educativo de Andalucía 2005-06, 2006-07, Sevilla, Consejería de Educación de Andalucía.

Consejo Escolar de la Comunidad de Madrid (2012) 2012 Informe sobre la situación de la Enseñanza no Universitaria en la Comunidad de Madrid; Madrid, Consejería de Educación, Juventud y Deporte.

Consejo Escolar de la Comunidad de Madrid (2008) Informe sobre la situación de la Enseñanza no Universitaria en la Comunidad de Madrid Curso 2005-2006. Madrid, Consejería de Educación, Juventud y Deporte.

Consejo Escolar de la Comunidad de Madrid (2009) Informe 2009 sobre la situación de la Enseñanza no Universitaria en la Comunidad de Madrid Curso 2007-2008. Madrid, Consejería de Educación, Juventud y Deporte.

Consejo Escolar de Euskadi (2012) Informe sobre la situación de la enseñanza en Euskadi, 2008-2010, VitoriaGasteiz, Consejo Escolar de Euskadi.

Consejo Escolar de Euskadi (2010) Informe sobre la situación de la enseñanza en Euskadi, 2006-2008, VitoriaGasteiz, Consejo Escolar de Euskadi.

Ley 14/1970, de 4 de agosto, General de Educación y Financiamiento de la Reforma Educativa, modificada por Ley 30/1976, de 2 de agosto. (B.O.E. de 6 de agosto de 1970, modificación at B.O.E. de 3 de agosto de 1976) en: www.cyberpadres.com/legisla/boe_14.pdf

Ley Orgánica 8/1985, de 3 de julio, Reguladora del Derecho a la Educación (BOE de 4 de Julio de 1985), en: http://noticias.juridicas.com/base_datos/Admin/lo8-1985.html

Ley Orgánica 1/1990, de 3 de octubre, de Ordenamiento General del Sistema Educativo (BOE de 4 de octubre de 1990), en: http://www.uclm.es/profesorado/Ricardo/LOGSE2.htm 
Ley Orgánica 9/1995, de 20 de noviembre, de la Participación, la Evaluación y el Gobierno de los Centros Docentes (BOE de 21 de noviembre de 1995), en: http://noticias.juridicas.com/base_datos/derogadas/R1-LO9-1995. T4.html

Ley Orgánica 10/2002, de 23 de diciembre, de Calidad de la Educación (BOE de 24 de diciembre de 2002), en: www.boe.es/ boe/dias/2002/12/24/pdfs/A45188-45220.pdf

Ley 1/1993, de 19 de febrero, de la Escuela Pública Vasca (BOPV de 25 de Febrero de 1993), en: http://noticias. juridicas.com/base_datos/CCAA/pv-11-1993.html

Ley 2/1993, de 19 febrero, de Cuerpos Docentes de la Enseñanza no Universitaria de la Comunidad Autónoma del País Vasco (BOPV de 25 de Febrero de 1993), en: http://noticias.juridicas.com/base_datos/CCAA/pv-I2-1993.html

Ley $3 / 2008$, de 13 de junio, de segunda modificación de la Ley de la Escuela Pública Vasca (BOPV de 23 de Junio de 2008), en: http://noticias.juridicas.com/base_datos/CCAA/PV-L3-2008.html

Ley 17/2007, de 10 de diciembre, de Educación de Andalucía (BOJA 26 de diciembre), en: http://www.lexureditorial.com/boe/0801/01184.htm 